\title{
Research on DFACTS Configuration and Coordinated Control in Premium Power Park
}

\author{
Wu Nan ${ }^{a}, *$, Chen Bing ${ }^{b}$ \\ State Grid Jiangsu Electric Power Company Research Institute, Nanjing, China \\ anicolanan@126.com, ${ }^{\mathrm{b}}$ cbsure@163.com \\ *corresponding author
}

Keywords: Premium Power Park, Power Quality, DFACTS, Configuration Principle, Coordinated Control Strategy

\begin{abstract}
Premium power park (PPP), which can provide reliable and economical power supply to customers based on customized power technology, is becoming a new choice to sensitive user groups. In this paper, the configuration principle and coordinated control strategy of DFACTS in PPP are analyzed. As the basis, configuration conditions of DFACTS are discussed. Further, configuration principles of multi-type DFACTS are proposed considering a series of typical power quality issues. Moreover, represented by multiple parallel APFs, a master-slave control strategy of DFACTS, is proposed to realize optimal control of DFACTS to improve power quality. Finally, via time-domain simulation in PSCAD, the effectiveness of the proposed coordinated control strategy is verified. This paper can provide positive references for planning, construction and control of PPP.
\end{abstract}

\section{Introduction}

With technology upgrading of electrical equipments and sustainable increase of sensitive loads, higher requirements to power quality of distribution network are put forward. To ensure safe and reliable power supply and reduce economic loss caused by power quality disturbances, lots of power quality control equipments such as DFACTS, are installed.

On this background, Premium power park, which can provide high reliability and economy of electricity service area, is becoming a new choice of sensitive user groups ${ }^{[1-4]}$. The concept of Premium Power Park (PPP) was proposed in 1992 by Westinghouse ${ }^{[5]}$, as an effective solution to meet the specific requirements of power equipments or customers. PPP can be defined as power service provided park, which can offers differentiated power quality level to meet different user needs based on customized power technology. It can provide basic services, additional services and high quality service to power customers. Therefore, PPP is especially suited for relatively concentrated loads and large users or areas, which have high power requirements, such as financial industry, IT industry and other modern industries ${ }^{[6-7]}$.

As the basis, various power quality control DFACTS equipments are utilized comprehensively in PPP. However, the lack of unified management and neglect of interaction of DFACTS equipments owned by different customers, will make it difficult to achieve good performances of governance 
and economy. Therefore, configuration and coordinated control of DFACTS are the core issues for PPP.

In this paper, the configuration principle and coordinated control strategy of DFACTS in PPP are deeply analyzed. And, a coordinated control example of DFACTS is given to show the realization of high power quality supply in PPP.

\section{Configuration Condition of DFACTS in PPP}

DFACTS installed in PPP include APF, AVG, DVR, SSTS and so on. Configuration condition of DFACTS in PPP is given as follows.

\subsection{Power Users Applied Customized Power Technology}

PPP is an important aspect of customized power technology. Power users who adopt customized power technology should follow the principles below.

(a) Wholeness.

Power users usually have sensitive loads, important loads, and common loads at the same time. So whether the user is suitable for custom power technology should be determined by power loss and power failure impact of main loads or important loads.

(b) Setting price according to power quality.

In order to maintain and improve the overall power quality level of the park, and guide users to actively participate in power quality management, the principle of setting price should be followed to maximize the economic benefits of both power supply and consumption sides. Electricity price of power users should be determined according to the quality of power supply. The higher the level of power supply quality, the higher the price.

(c) Power supply classification for user internal loads.

User internal loads should be classified according to the degree of sensitivity, importance and pollution. For loads with different levels and types, the power supply wiring and power level selection are different. The more sensitive and more important the load, more reliable the chosen power supply wiring and the higher the power quality level.

(d) Influence degree.

Economic loss, political impacts, environmental impacts and social impacts caused by power outage of different power users are different. The power users, which have the wider range of power loss and influence, is more suitable for customized power technology.

\subsection{Load Classification}

In the park, different users or equipment need different power supply quality. Load classification is the basis for premium power supply in PPP.

Load classification has two basic principles.

(a) According to the load sensitivity of power quality disturbance. In this principle, load can be classified as extremely sensitive load, sensitive load and ordinary load.

(b) According to loss degree caused by power quality events. In this principle, load can be classified as follows. In this principle, load can be classified as very important load, important load and ordinary load. 


\subsection{Power Supply Quality Classification}

Power supply quality classification is relevant to different power quality indicators and their scope. Power quality indicators are usually divided into two types, namely, continuous type and event type. The former includes harmonics, voltage deviation, frequency deviation, three-phase imbalance, voltage fluctuation and flicker, and so on. The latter includes voltage sag, short interrupted and so on. Power supply quality of PPP can be classified as three grades.

(a) A-level power supply.

A-level power supply is the basic power quality level in the park. Double-loop power supply from different power sources is adopted.

(b) AA-level power supply.

On the basis of A-level power supply, customized power equipment is installed and backup power supply is equipped.

(c) AAA-level power supply.

On the basis of AA-level power supply, energy storage equipment such as uninterruptible power supply (UPS) is equipped.

\section{Configuration Principles of DFACTS in PPP}

The configuration of DFACTS in PPP should meet following three principles:

(a) Ensure power supply quality of PPP to meet corresponding levels of requirements. Meanwhile, take the economy into account.

According to the load classification, the extremely sensitive load, sensitive load and ordinary load, are expressed as L3 load, L2 load and L1 load, respectively. According to the power supply quality classification, the A-level power supply, AA-level power supply and AAA-level power supply, are expressed as PQ1 power supply quality, PQ2 power supply quality and PQ3 power supply quality, respectively. In order to ensure power supply quality of PPP to achieve corresponding levels of the requirements and take economy into account, different levels of power supply should be provided to different levels of load, such as PQ1 $\rightarrow$ L1, PQ2 $\rightarrow$ L2, PQ3 $\rightarrow$ L3.

(b) Follow the principle of centralization and distribution.

Different DFACTS equipments have different functions. DFACTS equipments should be configured reasonably according to equipment features and power grid demand. L3 load should intensively install multi-type DFACTS equipments; while L1 load can install 1 or 2 DFACTS equipments according to demand. Load-oriented DFACTS equipments should be installed nearby the target load. Grid-oriented DFACTS equipments should be installed on the important bus. APF, DVR and similar equipments should be distributively located at the load side. SVG, SVC, TSC and similar equipments can be concentrated installed on the bus, which plays an important role in the whole voltage of PPP.

(c) According to the demands of classification of load power quality requirements and classification of power supply quality levels, customized power equipment should be configured reasonably. Concretely, functions of typical DFACTS equipments are shown in Table1. 
Table 1 Functions of typical DFACTS equipments

\begin{tabular}{|c|c|c|c|c|c|c|c|}
\hline $\begin{array}{c}\text { Equipment } \\
\text { Subject }\end{array}$ & DVR & SSTS & SVG & SVC & UPQC & APF & ESS \\
\hline Voltage sag & $※$ & $※$ & $\bullet$ & $\bullet$ & $※$ & & $※$ \\
\hline Voltage short interruption & & $※$ & & & & & $※$ \\
\hline Overvoltage & $\bullet$ & $\bullet$ & $\bullet$ & $\bullet$ & $\bullet$ & & $\bullet$ \\
\hline Under voltage & $\bullet$ & $\bullet$ & $\bullet$ & $\bullet$ & $\bullet$ & & $\bullet$ \\
\hline Voltage fluctuation and flick & & & $※$ & $※$ & $\bullet$ & & $\bullet$ \\
\hline Voltage unbalance & $\bullet$ & & $※$ & $※$ & $※$ & & \\
\hline Harmonics & $\bullet$ & & $※$ & $※$ & $※$ & $※$ & \\
\hline Power factor & & & $※$ & $※$ & $※$ & $※$ & \\
\hline
\end{tabular}

Note: $※$ represents typical applications of the equipment. represents the functions that the DFACTS equipment can achieve.

In order to achieve different levels of power supply, different combinations of DFACTS equipments are required. If a small number of DFACTS equipments are used, the power quality of the loads is difficult to meet. If too many DFACTS equipments are used, the economy will be poor. Therefore, configuration of different DFACTS equipments should be based on actual needs. Figure 1 gives DFACTS configuration principle for different power supply level.

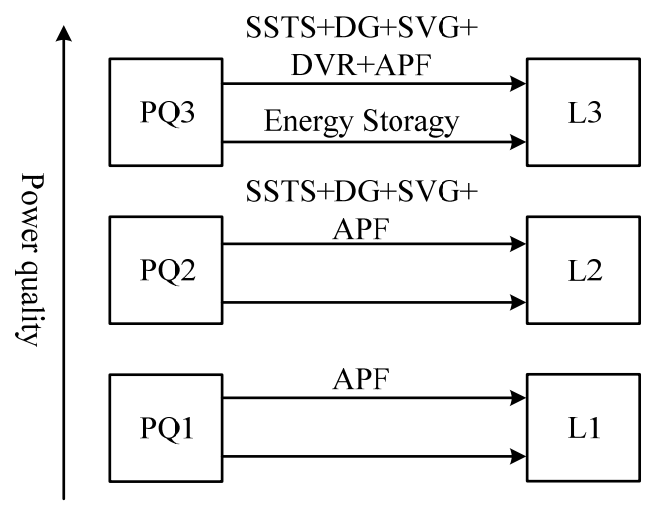

Figure 1 DFACTS configuration for different power supply level

Optimization configuration of DFACTS not only can improve power quality in the PPP, but also can promote the economy of PPP.

\section{Coordinated Control of DFACTS Equipment in PPP}

In this section, coordinated control of multiple DFACTS equipments in PPP is discussed. Limited by space, the coordinated control of multiple parallel APFs is selected as the example to give detailed illustrations.

Concretely, a master-slave control strategy of APFs, is proposed to realize optimal control of APFs to improve power quality as follows.

1) One APF is used as the master device and the other APFs are set as slave devices. 
2) The master device detects the electric quantity and determines the number and the corresponding compensation capacity of APFs that need to be inputted. And, as shown in Figure 2, the master will send switching commands and compensation capacity commands to other slave APFs.

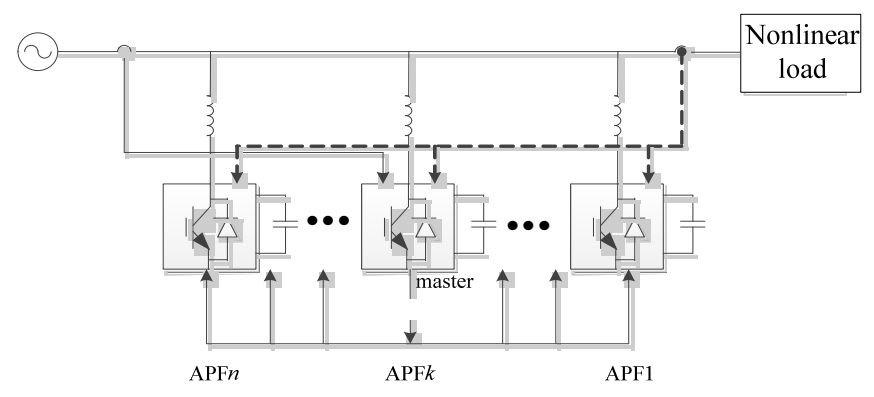

Figure 2 Coordinated control diagram of multiple parallel APFs

In Figure 2, $n$ same DFACTS equipments can be seemed as the singe equipment whose capacity is expanded $n$ times. For example, assume that the capacity of a single APF is $\mathrm{S}_{\mathrm{APF}}$ and the required compensation capacity is $\left[k \mathrm{~S}_{\mathrm{APF}},(k+1) \mathrm{S}_{\mathrm{APF}}\right]$, then $k$ slave APFs should be put into in addition to the master APF.

The master APF detects the load side current, and then calculates the number of APFs needed to be put into and the compensation capacity (proportional coefficient) of each APF. Further, each slave APF calculates the corresponding command value according to detected load current, and then multiplies the received proportional coefficient to obtain the final command current with the open loop control. The master APF adopts the closed loop control strategy of detecting the grid current to compensate the remaining harmonics of grid side.

\section{Time-domain Simulation Results}

To verify the effectiveness of the proposed coordinated control strategy, a model with two APFs is built up in PSCAD/EMTDC as shown in Figure 3. APF1 is the master device using closed-loop control strategy. APF2 is the slave device using open-loop control strategy. Assume that capacity of APF1 is same as capacity of APF2.
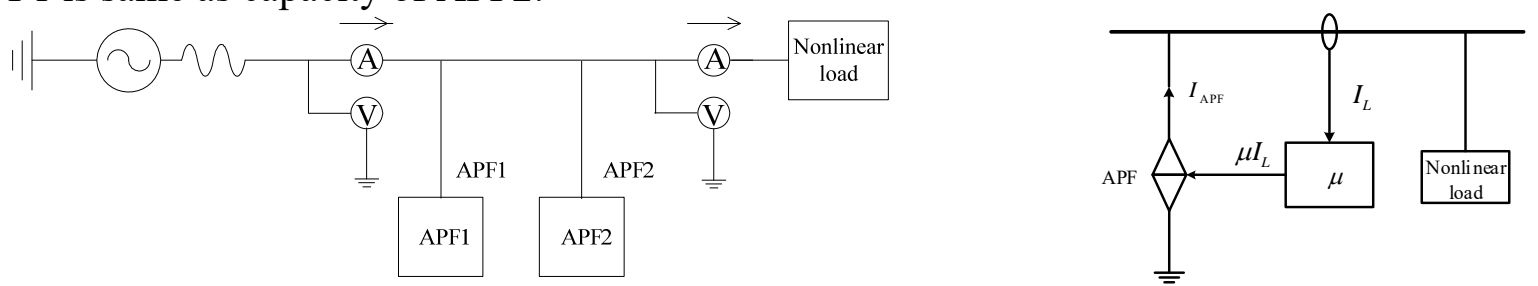

Figure 3 Simulation model diagram

Figure 4 Equivalent mathematical model of APF

Equivalent mathematical model of APF is shown in Figure 4. APF is equivalent to a controlled current source, and its mathematical model is expressed as (1).

$$
I_{\mathrm{APF}}=\mu I_{\mathrm{L}}
$$

In (1), $I_{\mathrm{L}}$ is load current, $I_{\mathrm{APF}}$ is current emitted by APF, and $\mu$ is harmonic compensation rate. Simulation results of Figure 3 are shown as follows.

(a) Single APF performance test.

Figure 5 and Figure 6 show the simulation waveforms of APF1 using open-loop current control. Figure 7 and Figure 8 show the simulation waveforms of APF2 using close-loop current control. 
Figure 5 and Figure 7 show current of nonlinear load side, APF side and grid side respectively. Figure 6 and Figure 8 show FFT results of nonlinear load side and grid side respectively.

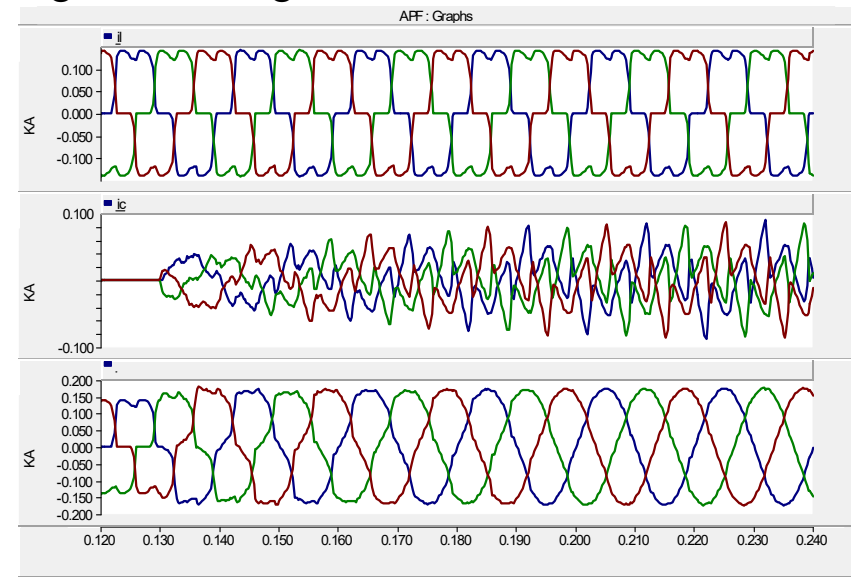

Figure 5 Simulation current waveforms of APF1

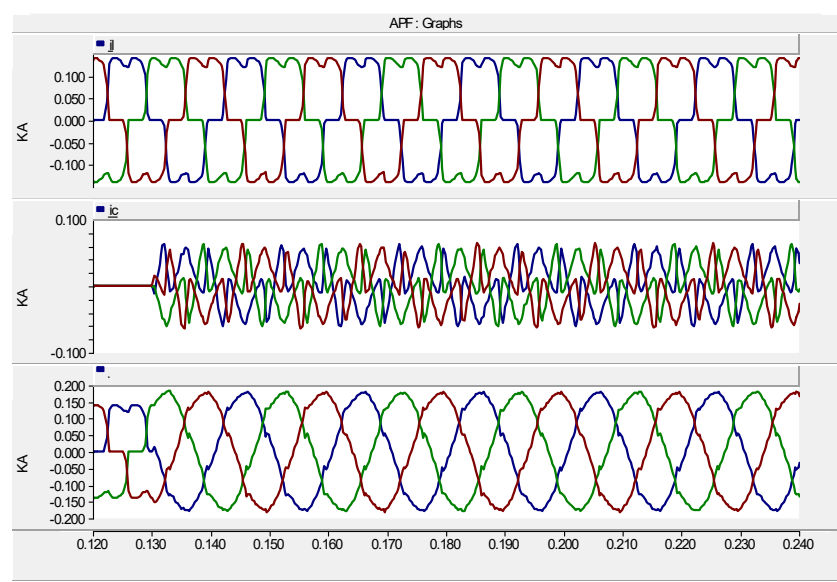

Figure 7 Simulation current waveforms of APF2

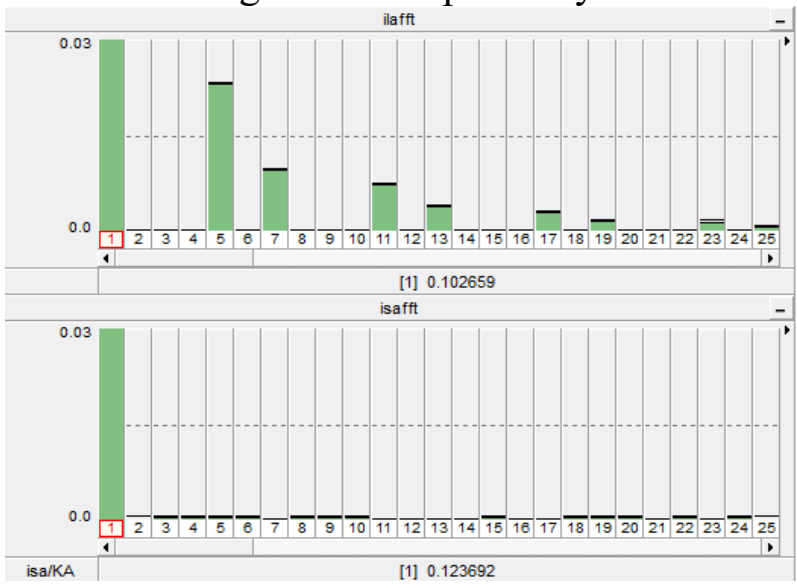

Figure 6 Simulation current spectrum of APF1

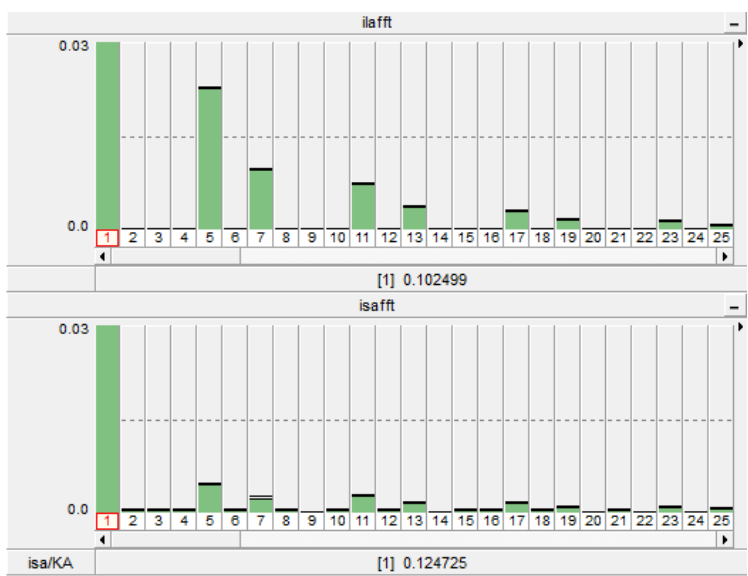

Figure 8 Simulation current spectrum of APF2

By comparing the simulation results, it can be seen that two APFs with different control strategies can realize the harmonic compensation of nonlinear load. The response speed of openloop current control is faster, while control accuracy of open-loop current control is not as good as closed-loop current control.

(b) Two APF coordinated control test.

Figure 9 shows the currents generated by two APFs. Figure 10 shows the grid side current.

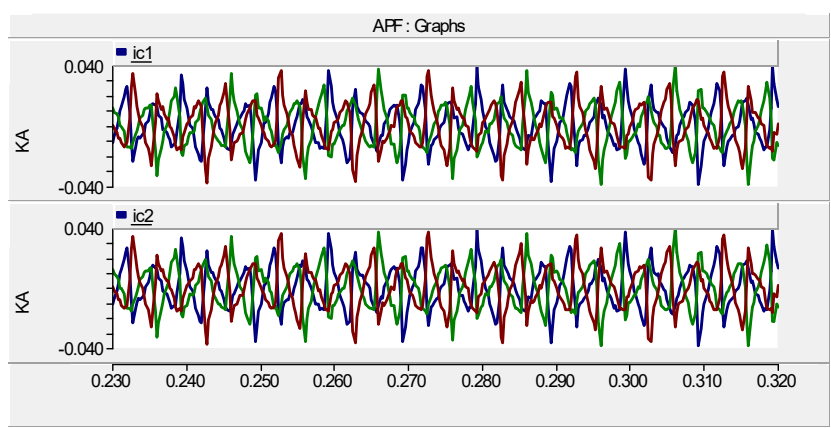

Figure9 Current waveforms of two APFs

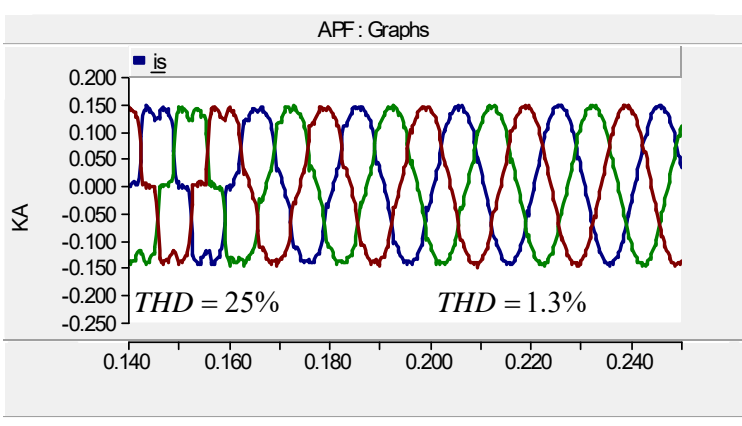

Figure10 Grid side current waveforms 
From simulation results in Figure 9 and Figure 10, it can be seen that currents generated by two APFs are almost the same. After APFs are started in 0.16s, THD of grid side current decreases from $25 \%$ to $1.3 \%$.

The simulation results show that, under the coordination control strategy proposed in this paper, multiple APFs can run simultaneously and distribute the corresponding load according to their capacity.

\section{Conclusion}

In this paper, the configuration principle and coordinated control strategy of DFACTS in PPP are analyzed. Via time-domain simulation in PSCAD, the effectiveness of the proposed coordinated control strategy is verified. This paper can provide positive references for planning, construction and control of PPP.

\section{References}

[1] Domijan Jr A, Montenegro A, Keri A J F, et al. Custom power devices: an interaction study[J]. Power Systems, IEEE Transactions on, 2005, 20(2) : 1111-1118.

[2] Nielsen J G, Newman M, Nielsen H, et al. Control and testing of a dynamic voltage restorer(DVR) at medium voltage level[J]. Power Electronics, IEEE Transactions on, 2004, 19(3): 806-813.

[3] Meral M E, Teke A, Bayindir K C, et al. Power quality improvement with an extended custom power park[J]. Electric Power Systems Research, 2009, 79(11): 1553-1560.

[4] Kaura V, Blasko V. Operation of a phase locked loop system under distorted utility conditions[J]. IEEE Transactions on Industry Applications, 1997, 33(1): 58-63.

[5] Vilathgamuwa M, Ranjith Perera A A D, Choi S S. Performance improvement of the dynamic voltage restorer with closed-loop load voltage and current-mode control[J]. Power Electronics, IEEE Transactions on, 2002, 17(5): 824-834.

[6] Corsi S, Pozzi M, Sforna M, et al. The coordinated automatic voltage control of the Italian transmission grid Part II: control apparatuses and field performance of the consolidated hierarchical system[J]. IEEE Transactions on Power Systems, 2004, 19(4): 1733-1741.

[7] Ghosh A, Joshi A. The concept and operating principles of a mini custom power park[J]. IEEE Trans on Power Delivery, 2004, 19(4): 1766-1774. 